\title{
Improvisation in Process
}

\author{
Bennett Hogg
}

\section{Introduction}

Improvisation and the process of social justice are cultural practices whose exact end points, when any individual endeavour is initiated, are unknown. Indeed, if the outcome of a social justice initiative was determined prior to its process, the judgment would be thought biased, that due process had not in fact been followed. ${ }^{1}$ In this article, I suggest that musical improvisation and social justice share many practices and concerns, some more explicit than others. In particular, I examine ways that improvisation and social justice processes might interrogate and challenge the respective ontologies of the "musical work" and the "law," and on the basis of this examination, characterize both as "mediations" rather than applications of a priori categories. Complementing this, I also examine some specific conditions of listening and ways in which listening might be differently configured, insofar as such an examination impacts our understanding of listening in the exercise of both music and social justice. ${ }^{2}$

It is important to be aware, however, of the problems of mapping an abstraction of one thing onto an abstraction of something else. Although (post-)structural analysis can be useful for speculating on the inter-relationships between perceived patternings, the harmonizations that may be found across phenomena must not marginalize the significant dissonances that should also claim our attention. Structural similarities are not enough: improvisation and judgment are not abstractions to be mapped onto one another, but concrete cultural practices. Apparent similarities, then, should not be carelessly accepted as de facto connections, but should initiate deeper interrogation of the phenomena under investigation.

Judgments affected by racial, class, or gender stereotypes can destroy lives, but few lives are ruined by music improvisation. Indeed, for many free improvisers the notion of "bad" improvisation evokes harmful commercial ideologies of technical skill. At its most effective, free improvisation values the collective (culture in its broadest sense) over any absolute, individualist attitudes, and affords a meeting place for cultural and social negotiation in the face of largely un-negotiated power structures that enforce law and constrain identity based on class, race, gender, and sexuality. An improviser who has never felt dominated or marginalized, however, is probably a very rare creature. Furthermore, although free improvisation has experts who are accorded high status, I have found myself playing alongside the likes of Evan Parker, Steve Beresford, or Eddie Prévost-a situation that would be inconceivable for an amateur in classical music, rock, or jazz. Unlike more professionalized cultural practices, improvised music remains inclusive, unconcerned with how technical musical ability might be judged elsewhere. ${ }^{3}$

Christopher Small sees the classical concert tradition as the apotheosis of how professionalization has limited musicking to a strictly ritualised consumption of musical works and a severe and limiting set of laws about musical organization (Small 94-109 and passim). ${ }^{4}$ This tradition presents us with a model of harmony, but one maintained by obedience and acquiescence to a set of a priori laws. In its wilder dreams, free improvisation would model a just society that includes all who voluntarily participate (Small's critique of the classical tradition emerges, in part, from his many years as an improviser). While improvisation does not indulge in the wholesale glorification of the untutored as a matter of principle (though some practitioners do), it does, unlike many other musical practices, make proper space for it. John Stevens' Search and Reflect, for example, deploys insights from improvisation-the significance of gesture, of collectively produced sound; the "greater-than-the-sum-of-itsparts-ness" of improvised music; the local and contingent nature of musical meaning, generated through participation rather than consumption-to resist the idea that musical education can be reduced to the learning of approved works and techniques, setting out an alternative musical syllabus grounded in listening, personal invention, collective learning and expression, and an embodied consciousness that develops through collective experience.

Stevens' approach to developing musical creativity follows a visceral but playful, from-the-ground-up practicality in which all members of a culture have musicality embodied within themselves, but where realization of that musicality may be inhibited by a priori expectations such as notions of playing the piece "properly." Stevens' approach is congruent with more recent theories of creativity grounded in the circulation, decontextualization, and recontextualization of cultural "materials" (see Toynbee; Born; and Waters). Rather than romanticised mystification, where art making is the exclusive preserve of the individual artist, these positions understand artistic generation as something that emerges through collective acculturation.

While I have sounded a caveat against uncritically seizing upon structural similarities, I have also advocated for their potential as signposts to more productive exploration. l'd like to explore, therefore, how concepts of "the work" in music (the existing, allegedly repeatable musical composition) can be understood as obstacles to improvisation, and to then think out from this point how "law" might under certain situations be a structurally similar obstruction to social justice. 


\section{The Musical Work}

Arguments about the ontology of the musical work are legion (Pietras and Robinson 552-553; Ridley 206; Talbot; Ingarden) and fraught with difficulties, one reason why it seems such a pervasive and powerful ideology, its intangibility itself resisting critique. For Ingarden (and earlier Hanslick), the work is separate from any instance of its performance, whereas others see the work being "realized only in performance" (Treitler 490). Ingarden, however, refuses to reduce the work to its written form, whereas Goodman insists that "the musical work is identical to the score" (qtd. in Ridley 203).

Levinson resists the notion that musical works can be reduced to the "sound structures" they make ("What a Musical Work Is" 6). His argument, implicit in his limiting his observations to scored music of the Western Art Music tradition, relies on a rather conservative understanding of issues such as originality, authorship, and so forth:

The notion that artists truly add to the world, in company with cake-bakers, house-builders, law-makers, and theory-constructers, is surely a deep-rooted idea that merits preservation if at all possible. The suggestion that some artists, composers in particular, instead merely discover or select for attention entities they have no hand in creating is so contrary to this basic intuition regarding artists and their works that we have a strong prima facie reason to reject it if we can. If it is possible to align musical works with indisputably creatable artworks such as paintings and sculptures, then it seems we should do so. (8)

Levinson's elaborations on this idea are, furthermore, predicated on a series of hypothetical thought experiments that are unlikely in the extreme.

Treitler, however, is critical of the thought experiments of Levinson and notes that, although such fantastic projections are suited to abstract discourse,

this inquiry has, paradoxically, been directed from a very particular historical stance. And what it conveys is not the existential condition of musical compositions under any circumstance by virtue of their being musical compositions, but rather beliefs about the condition of a limited number of high-art compositions of the European tradition . . . music of the "common practice" period, but by no means all such music. (Treitler 484, emphasis in original)

Such enquiries do not, for Treitler, engage in a philosophy of musical ontology, but rather extrapolate norms from particular moments in one limited strand of musical history.

When we improvise, we may make "music," but not, I argue, a musical "work." Free improvisation neither needs nor is best evaluated in terms of the "work concept" (see also Peters 36-43). In free improvisation, there is potential energy, but the music arises through a dynamic and shifting concatenation of memory, reactions, gestural interplay, indecision, clumsiness, and chance; internalised sonic and instrumental strategies sedimented over years and years; a pregnant assemblage of potentialities brought by each participant. To suggest that this results in a musical work is to miss the point, and to derail the chance of establishing a more progressive, alternative view. We can make a work by improvising, but to avoid being stifled or distracted, to really explore its full potential as an epistemic practice, improvisers need to be able to leave the notion of "the work" behind. Improvisations are always a few steps away from being "works" in the conventional sense, and this is their strength: they generate a body of practice, but there is no absolute completion.

For many authors, a "closed, unified formal structure" is "one of the recurrent conditions for work status" (Treitler $496, n 13)$. Such a model of musical ontology is highly resonant with many critical views of law and the exercise of justice. Ramshaw, for example, draws parallels between the relationship of judgment to law and how musical improvisation relates to more formal, established musical structures, drawing on Derrida's critique of spontaneity and invention insofar as judgment is singular and specific whereas law is universal and general (Ramshaw 6-8).

For Dahlhaus, the closed status of the work marks a remarkably persistent historical idea: though most musicologists understand this concept as arising in parallel with the nascent ideas of musical autonomy towards the end of the eighteenth century (Goehr; Dahlhaus; Treitler; Talbot), it has dominated thinking about music more generally. There seems to be nothing controversial, for example, in envisioning an improvisation as something "singular, complete, and containable" (Ramshaw 8), but such close conformity to the idea of the musical "work" is quite contrary to my own experience with improvising. Because there is no determining text and the listening positions of the participants are multiple and plural, an improvisation is necessarily 
- $\quad$ Plural. ("I thought your solo was great." - "Really? It felt awkward to me." - "Was that a solo? Seemed like you were dueting with the bass.")

- $\quad$ Open-ended. ("That didn't feel to me like we reached the end." - "Oh, I could have stopped ten minutes back.")

- If not actually "uncontained," then surrounded with only porous boundaries. ("There was a woman at the front really getting into it, and I was playing off her.")

Dahlhaus also sees memory, and reflection back upon the listening experience, as one of the ways in which a musical work can be conceptualized as a whole:

[Music's] objectivity is displayed not so much immediately as indirectly: not in the moment when it is sounding, but only if a listener, at the end of a movement or section, reverts to what has passed and recalls it into his present experience as a closed whole. (11)

Does this mean that an improvisation can be "a work"? A significant problem is that a work must be repeatablenot literally (the argument that the work cannot be reduced to its performances), but ontologically. There must be an "existent" which stands as "the work" that cannot only be repeated, but which is determined in great part by the fact of its being repeatable. For Derrida, this is the condition of all signification: "iterability," the inescapable condition for an invention to be considered an invention (5-6). A recorded improvisation can be replayed, and remembered, and as such be retroactively experienced as a whole, and is in that sense repeatable. The recording, or the memory, is not the improvisation however, any more than Magritte's painting is a pipe. An improvisation cannot be repeated and remain an improvisation: it may become something like "a work," but it will not be an improvisation.

Some things cease to be themselves when they are repeated-surprises, for example-and a law cannot remain just if it is simply the re-application of the same to the different. As precedents accumulate, application changes the law, just as repetition (in different concerts and recordings) changes a musical work. Repeatability is mutability.

Iterability is slightly different: rather than making improvisation impossible, it actually feeds it. Such iterability is primarily social, limited not to the persistence or repetition of traces through time, but always already present in any instance of musicking or other socio-cultural act. Elsewhere, I have written about the ways improvisers carry within themselves a rich history of embodied experience and ability ("Embodied Consciousness"; "Enactive Consciousness"). In an improvising collective, participants hold within themselves vast archives of memory, experience, skill, and imagination: a mutable ecosystem wherein iterability, but not the straightforward repetition of works, is possible.

\section{Being Heard}

From the discussions held at the Sonic Arts Research Centre (SARC) during the Just Improvisation symposium, ${ }^{5}$ the most resonant idea for me was the notion of "being heard." Psychoanalysts have known for a long time that effective psychoanalytic treatment depends as much upon being heard as on anything the analyst says. Graybar and Leonard, for example, state that "the mortar of the therapeutic relationship is listening. Accurate empathy conveyed through listening transcends theoretical orientation and connects many successful psychotherapies ... Listening and being listened to are the cornerstones of psychological development, psychological relatedness, and psychological treatment ... Being listened to creates . . . a sense of coherence, safety, belonging, and value" (2-3). During the first panel of the Just Improvisation symposium, barrister Denise McBride QC 6 mentioned several times that parents are often "not heard" amidst the crowd of "experts" testifying and arguing for courses of action-that sometimes, when they're listened to, families have their own answers to their problems, but that "there is no mechanism to hear them."

Several times during the symposium, participants observed that family members are more often able to accept a judgment, even if it goes against them personally, if they feel that they have been heard. For one to "feel heard," a degree of exchange must occur. Fitzgerald and Leudar underline the importance of psychoanalytic listening that performs itself through the use of continuers ("and then . . . ?") and non-judgmental interjections ("response tokens" such as "I see" or "aha") on the part of the therapist/listener. The so-called "silent" treatment of certain Lacanians (where the analyst says nothing and thus creates an open space into which the analysand is forced to speak) seems to eschew this performance listening, yet if we shift the scenario from the psychiatrist's couch to a soloist and a listener, the social dynamics are much less unusual: one way many musicians imagine they have been heard is when the audience sits in (apparently) rapt silence. For me, this marks a suggestive point at which different kinds of listening can be understood as mediating one another.

One speaks into relative silence, and then the subject of that address replies, such a sequence proving to the interlocutors that they have been heard by one another. During the Just Improvisation symposium, Ellen 
Waterman concisely outlined how to engage in the process of improvisation: "Listen. Recognise. Respond." Listening and recognizing can, of course, describe any act of listening: the weather forecast, "Mars" from Holst's The Planets, the kettle boiling; "listening, recognising, and responding," however, constructs an environment specifically suited to improvisation, one where each category marks subjective and socio-culturally organized acts. Through a concatenation of such sequences, multiple interlocutors can arrive at judgments, or an improvised musical performance can happen. So far, the structural connection between social justice and improvisation holds, but what happens when we analyze the equally important differences behind this strong resemblance. What kinds of listening actually happen in these two different scenarios?

Imagine a scenario where someone accused of abusing a child is confronted by four different people all talking at the same time: this is precisely the sort of sonic environment in which an improvisation unfolds. It is just as important for an improviser to be heard (otherwise why participate?) as a defendant in family court, but in my experience, the nature of listening and the actualization of "being heard" do not always fall so cleanly into the model of "listen, recognize, and respond," something Waterman herself made clear was a reductive cipher from which to begin thinking about improvising, rather than a full representation. I would add to Waterman's formula a fourth term: "anticipation," the moment during which one plays something that fits with what everyone else is doing, but before hearing the response. Responding might actually precede listening and yet still be "on the nail," even if the application of this dynamic to social justice would be-in the very literal sense-prejudiced.

If the requirement is either attentive silence or explicitly performed interlocution, evidence that one is being heard can be ambiguous when musicians are performing simultaneously. In my university classes, new participants often feel "lost" in group improvisations, grasping onto call and response structures for reassurance that they are contributing. These anxieties pass as they find a place within the polyphony, a process that is difficult to conceptualize in more linear discourses like a conversation or a hearing. In musical improvisation, being heard seems more like Merleau-Ponty's idea of "being honeyed," where honey "allows itself to be grasped," but also "grasps the hands of whoever would take hold of it" (46). ${ }^{7}$ Such reciprocity, where one feels both the honey itself and how honey makes one's fingers feel, approximates how one can feel heard in an improvisation. Rather than another player's explicit response, it is the music itself that reassures us: as we play, the music we hear changes, and through this change we find ourselves heard.

Jerrold Levinson ("Musical Expressiveness" 107 and passim) proposes that musicians and listeners sense in music a "persona" with its own agency, one grounded on the idea that an expressivity must be the expressivity of a persona. I guard against too literal an invocation of this persona, as the idea is too anthropomorphic, but music, especially when collectively produced, does seem to have its own ontology, to be more than the sum of the contributions of its participants. The music "itself" seems to become an agent.

The practical Musical Improvisation Workshop at the Just Improvisation symposium brought this sense of music emerging with its own agency and ontology keenly into focus, beginning with a series of duets (passed around the large circle of musicians in relays) as a way for everyone to introduce themselves. This approach is frequently used in large collective improvisations (such as Eddie Prévost's meetings in London) and, when conditions are favourable, can lead to a strong sense of group coherence and connectivity; it seems to also model, however, an a priori idea that an improvisation is a combination of discrete elements rather than something that emerges from and is supernumary to the individual elements found within it. This latter perspective is actually how I experience group improvisation, and several others at the workshop concurred with this: we simply "sound" or "play," allowing the improvisation to emerge as individual members listen, react, and anticipate. Such an approach, where individuals make their own sense of a complex musical "reality," is close to Gibson's ecological analysis of human perception and cognition: rather than a sentient organism assembling information from "a kaleidoscopic inflow of sensations" (5), the musician is a participant in a wider ecosystem where perception of self and the environment becomes a "self-tuning process" (Clarke 19, emphasis added).

In music, "the ecological approach views perceptual learning as progressive differentiation, perceivers becoming increasingly sensitive to distinctions within the stimulus information that were always there but previously undetected" (Clarke 22). A strategy for group improvisation, then, which makes time to see "what happens," and out of which individuals differentiate their own spaces for participation, resonates more strongly with how we perceive the world than the atomistic model of building up from smaller elements. If we transpose this approach into a judicial process, we encounter again the same problem of four people talking at the same time, just with more people; however, there is something to be taken from such an imagining. In the Just Improvisation symposium panel mentioned above, Denise McBride QC noted the danger of proceedings disintegrating into a series of dissenting "experts" vying for precedence, with those at the centre of the process-family, victims, the abusers themselves - stranded outside, subject simply to data collection and a ruling made without their input. I generally dislike rhetorical questions, but can we apply musical experiences (where we have to hurl, sidle, or otherwise insert ourselves into a plurality of information) towards constructing another way to approach the judicial scenario? 
Ellen Waterman, in her keynote address, suggested that difference is not something to resolve, but to negotiate. The Western tradition of rhetoric, of asserting and proving an argument-applied liberally in narratives, scientific documents, philosophical treatises, and (arguably) "classical" Western compositions—does not mesh with such a principle. Family law must always be open to improvisation: the absence of a definitive "work" keeps the door open for negotiation as interpersonal dynamics among families change.

\section{Mediation-In Music and In Justice}

The tools, skills, and critical approaches I am advocating for here cannot be determined outside of the setting in which they are deployed. Instead, they condense through practice, and might properly be said to be phenomenological rather than instrumental. As Trigg puts it, "the familiar idea that definition precedes exposition" is not a viable approach for a phenomenological enquiry:

Rather than bludgeoning the reader with a fixed definition of . . . key terms at the beginning, and then insisting that the reader remain heedful of those definitions throughout, I believe [the] themes [of the inquiry] must be returned to, forever exploring their formations and recessions. (3)

To be truly "collective" and "social," both improvisation and social justice must not shy away from complexity and contradiction. One source of such complexity is how works, acts, and technologies (from writing to file-sharing) constantly mediate one another. Musical improvisation is not a singular, complete, containable phenomenon; but rather a consensual, collective mediation across cultural materials that may include works, rules, styles, techniques, and personal attitudes. An improvisation does not need to be transgressive, disruptive, or unprecedented-from my own experience, most, in fact, are not.

Just as the notion of a musical work may obscure a more nuanced understanding of improvisation, does not the notion of "judgment" as the conclusion of a process also obstruct inclusive judging? The absence of a work can imply the corollary absence of a normative frame, but this is not to say that there is no normativity present. Instead, the normative is manifest in the habitus of improvising, and indeed of music, in a culture. Some actions can lead to a concatenation of musical elements that are not resolvable to the satisfaction of the participants (as most improvisers will admit when such a circumstance occurs), but an unsuccessful improvisation, one that "didn't work," is something very different from the flawed or inadequate realization of a musical work. There is no "failure," as such, in part because there was no work to get wrong, but also because the experience adds to the ongoing development of each of the improvisers involved.

Georgina Born rejects any sense of autonomy for musical works and practices, insisting that all music exists in a distributed and mediated form, not in any kind of pristine, ontological condition. Talking specifically about jazz, she notes that its "ontology is primarily material and social" (27), but this is true for all musical and cultural phenomena: materials are actualized only within and through social action. The concept of a musical work is not wrong in any absolute, moral sense, but it simply doesn't stand up to a nuanced examination of its social operations.

We can't transpose practices from musical improvisation onto the judicial process, but we can allow insights from the former to inform emergent strategies in the latter. The term "mediation," while offering a less polarizing view of improvisation, also refers to the process whereby social workers, police officers, and lawyers interact with different members of a family to progress towards a just resolution to their problems. Collectivity is a human imperative; language, self-reflection, and culture (frequently invoked to differentiate us from the rest of creation) the more tangible surface effects that compel us to hear, sound, and negotiate with one another. Mediation, then, may be how musical improvisation and social justice can learn from each other and, by performing together with no rules other than the ones they negotiate, offer a model for a just and inclusive society.

\section{Notes}

${ }^{1}$ It may be coincidence that in German the word prozess refers both to a process as we might conventionally understand it in English and to a trial or court hearing, but I doubt this.

${ }^{2}$ As a music improviser, and someone whose teaching incorporates improvisation, my perspectives are most strongly informed by music. Participation in the Just Improvisation symposium in Belfast in 2015 (see below for more information), however, brought me into contact with social justice practitioners, and this, combined with many years spent leading community projects involving musical improvisation, has informed the potential connections I see between the two fields.

${ }^{3}$ An improviser who has never felt dominated, marginalized, or judged, however, is probably a very rare creature. I do not wish to suggest that humans are dominant over or marginalize one another as a matter of course, or that 
great institutionalized forms of oppression such as sexism and racism are equivalent to professional jealousies or judgments about taste, but however idealistic or aspirational a cultural practice may appear, the power relations of the related culture are inevitably manifested, particularly within explicitly social forms of musicking such as free improvisation.

${ }^{4}$ For Small, the Western classical music concert, and the ideology that surrounds and organizes it, risks disinheriting us from our "birthright": the basic human capacity for making music. Small predicates his critique on the reification of "Music-with-a-capital-M," which turns an activity into an object. "Musicking," the term Small proposes, stresses that music is a verb, not a noun (2), and includes under its purview many activities (preconcert socializing, foot-tapping, etc.) that would not be conventionally understood as Music.

5 Just Improvisation: Enriching Child Protection Law Through Musical Techniques, Discourses, and Pedagogies; held at the Sonic Arts Research Centre (SARC), Queen's University Belfast, 29-30 May 2015. For video documentation of the keynote, see translatingimprovisation.com/portfolio/symposium.

${ }^{6}$ In October 2015, Denise McBride QC was appointed judge of the High Court of Northern Ireland.

7 This phenomenological insight is also dealt with in specific relation to music and sound by Voegelin (6-11).

\section{Works Cited}

Born, Georgina. "Musical Mediation: Ontology, Technology and Creativity." Twentieth-Century Music, vol 2, no. 1, 2005, pp. 7-36.

Clarke, Eric. Ways of Listening: An Ecological Approach to the Perception of Musical Meaning. Oxford UP, 2005.

Dahlhaus, Carl. Esthetics of Music. 1967. Translated by William W. Austin, Cambridge UP, 1990.

Derrida, Jacques. Psyche: Inventions of the Other, Volume I. Stanford UP, 2007.

Fitzgerald, Pamela and Ivan Leudar. "On Active Listening in Person-Centred, Solution-Focused Psychotherapy." Journal of Pragmatics, vol. 42, 2010, pp. 3188-3198.

Gibson, J.J. The Senses Considered as Perceptual Systems. Houghton Mifflin, 1966.

Goehr, Lydia. The Imaginary Museum of Musical Works: An Essay in the Philosophy of Music. Revised ed., Oxford UP, 2007.

Graybar, Steven R. and Leah M. Leonard. "In Defense of Listening." American Journal of Psychotherapy, vol. 59, no. 1, 2005, pp. 1-18.

Hanslick, Eduard. The Beautiful in Music: A Contribution to the Revisal [sic] of Musical Aesthetics. Translated by Gustav Cohen, Novello, 1891.

Hogg, Bennett. "Embodied Consciousness as a Site of Cultural Mediation in Thinking about Musical Free Improvisation." Consciousness, Literature, Theatre and the Arts, edited by Daniel Meyer-Dinkgraf, Cambridge Scholars, 2010, pp. 266-275.

---. "Enactive Consciousness, Intertextuality, and Musical Free Improvisation: Deconstructing Mythologies and Finding Connections." Music and Consciousness: Philosophical, Psychological, and Cultural Perspectives, edited by David Clarke and Eric Clarke, Oxford UP, 2011, pp. 79-93.

Ingarden, Roman. The Work of Music and the Problem of Its Identity. Palgrave Macmillan, 1986.

Levinson, Jerrold. "Musical Expressiveness.” The Pleasures of Aesthetics. Cornell UP, 1996, pp. 90-125.

---. "What a Musical Work Is." The Journal of Philosophy, vol. 77, no. 1, 1980, pp. 5-28.

Merleau-Ponty, Maurice. The World of Perception. 1948. Translated by Oliver Davis, Routledge, 2008. 
Peters, Gary. The Philosophy of Improvisation. U of Chicago P, 2009.

Pietras, Monika and Lyn Robinson. "Three Views of the 'Musical Work': Bibliographical Control in the Music Domain." Library Review, vol. 61, no. 8-9, 2012, pp. 551-560.

Ramshaw, Sara. "Deconstructin(g) Jazz Improvisation: Derrida and the Law of the Singular Event." Critical Studies in Improvisation, vol. 2, no. 1, 2006, www.criticalimprov.com/article/view/81/188.

Ridley, Aaron. "Against Musical Ontology.” Journal of Philosophy, vol. 100, no. 4, 2003, pp. 203-220.

Small, Christopher. Musicking: The Meanings of Performance and Listening. Wesleyan UP, 1998.

Stevens, John. Search and Reflect. Community Music, 1985.

Talbot, Michael, editor. The Musical Work: Reality or Invention. Liverpool UP, 2000.

Toynbee, Jason. "Music, Culture, and Creativity." The Cultural Study of Music: A Critical Introduction, edited by Martin Clayton, Trevor Herbert, and Richard Middleton, 2nd ed., Routledge, 2012, pp. 161-171.

Treitler, Leo. "History and Ontology of the Musical Work." Journal of Aesthetics and Art Criticism, vol. 51, no. 3, 1993, pp. 483-497.

Trigg, Dylan. The Memory of Place: A Phenomenology of the Uncanny. Ohio UP, 2012.

Voegelin, Salomé. Listening to Noise and Silence: Towards a Philosophy of Sound Art. Continuum, 2010.

Waters, Simon. "Beyond the Acousmatic: Hybrid Tendencies in Electroacoustic Music." Music, Electronic Media and Culture, edited by Simon Emmerson, Ashgate, 2000, pp. 56-83. 